\title{
Designing a Beryllium-Free Deep-Ultraviolet Nonlinear Optical Material without Structural Instability Problem
}

\author{
Sangen Zhao, Lei Kang,," "Yaoguo Shen, "," Xiaodong Wang, ${ }^{\S}$ Muhammad Adnan Asghar, "," Zheshuai Lin, ,"f
} Yingying Xu, ", Siyuan Zeng, ${ }^{\dagger}$ Maochun Hong, ${ }^{\dagger}$ and Junhua Luo ${ }^{*}+{ }^{\prime}$

${ }^{\dagger}$ Key Laboratory of Optoelectronic Materials Chemistry and Physics, Fujian Institute of Research on the Structure of Matter, Chinese Academy of Sciences, Fuzhou, Fujian 350002, China

${ }^{\ddagger}$ Beijing Center for Crystal R\&D, Key Lab of Functional Crystals and Laser Technology of Chinese Academy of Sciences, Technical Institute of Physics and Chemistry, Chinese Academy of Sciences, Beijing 100190, China

${ }^{\S}$ Changchun Institute of Optics, Fine Mechanics and Physics, Chinese Academy of Sciences, Changchun 130033, China

"University of Chinese Academy of Sciences, Beijing 100049, China

\section{CONTENTS}

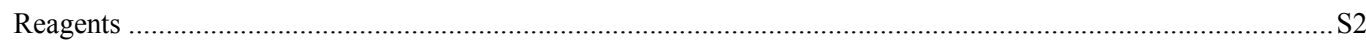

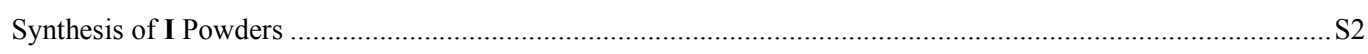

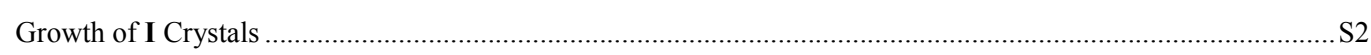

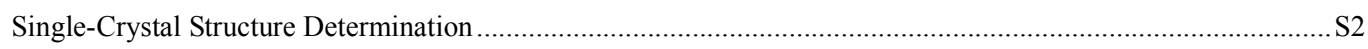

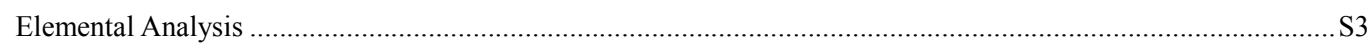

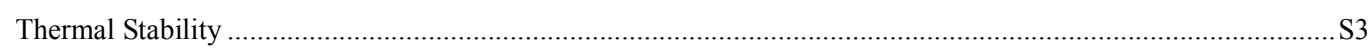

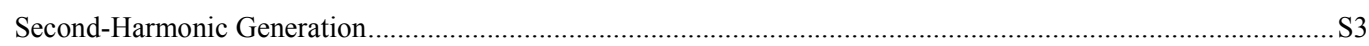

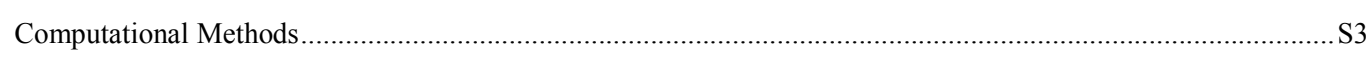

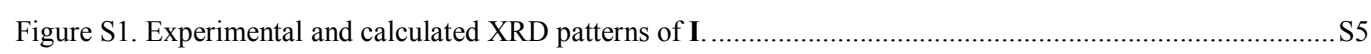

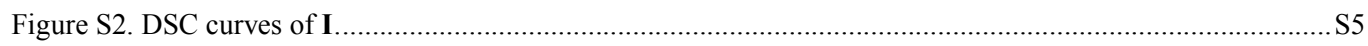

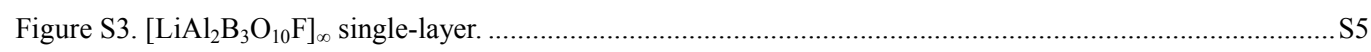

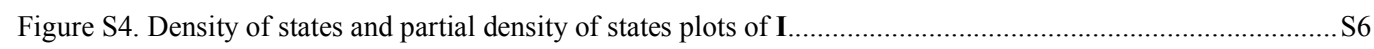

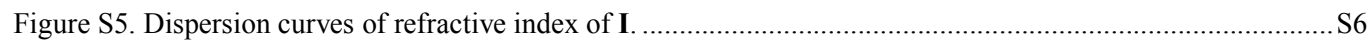

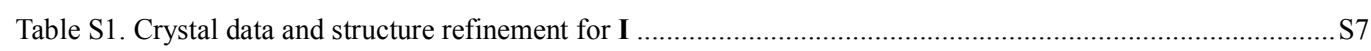

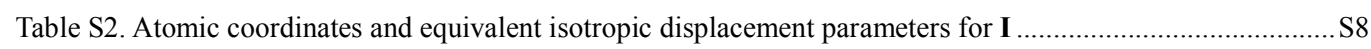

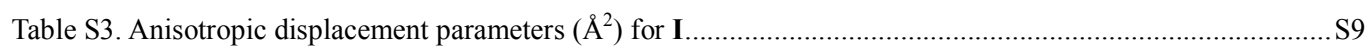

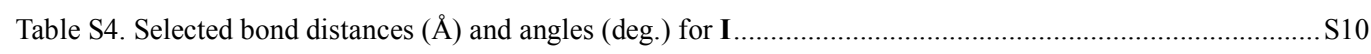

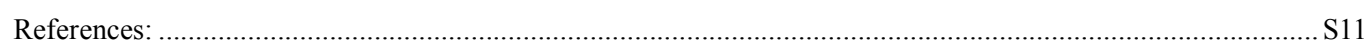




\section{Reagents}

$\mathrm{K}_{2} \mathrm{CO}_{3}$ (99.99\%), $\mathrm{BaCO}_{3}$ (99.998\%), $\mathrm{BaF}_{2}$ (99.99\%), $\mathrm{Li}_{2} \mathrm{CO}_{3}$ (99.998\%), $\mathrm{Al}_{2} \mathrm{O}_{3}$ (99.999\%), $\mathrm{LiF}(99.99 \%$ ), and $\mathrm{H}_{3} \mathrm{BO}_{3}(99.998 \%)$ were purchased from Aladdin and used as received.

\section{Synthesis of I Powders}

Polycrystalline I was synthesized by the traditional solid-state reaction techniques. A mixture of $\mathrm{K}_{2} \mathrm{CO}_{3} 20.73 \mathrm{~g}$ (0.15 mol), $\mathrm{BaCO}_{3} 59.20 \mathrm{~g}(0.30 \mathrm{~mol}), \mathrm{Li}_{2} \mathrm{CO}_{3} 3.69 \mathrm{~g}(0.05 \mathrm{~mol}), \mathrm{Al}_{2} \mathrm{O}_{3} 20.39 \mathrm{~g}(0.20 \mathrm{~mol}), \mathrm{LiF} 2.59 \mathrm{~g}(0.10 \mathrm{~mol})$, and $\mathrm{H}_{3} \mathrm{BO}_{3} 37.10 \mathrm{~g}(0.6 \mathrm{~mol})$ was thoroughly ground, slowly heated to $773 \mathrm{~K}$ at a rate of $10 \mathrm{~K} / \mathrm{h}$, and then sintered at this temperature for $24 \mathrm{~h}$. The products were ground thoroughly, heated to $923 \mathrm{~K}$ at a rate of $30 \mathrm{~K} / \mathrm{h}$, and then sintered at this temperature for $150 \mathrm{~h}$ with several intermediate grindings. The phase purity was confirmed by powder X-ray diffraction (XRD) analysis, which was carried out at room temperature on a Rigaku MiniFlex II diffractometer equipped with $\mathrm{Cu} K \alpha$ radiation in the $2 \theta$ range of $10-70^{\circ}$. The measured XRD pattern well matches the calculated one based on single-crystal XRD analysis (see Figure S1).

\section{Growth of I Crystals}

Single crystals of $\mathbf{I}$ were grown by the top-seeded solution growth method with the flux $\mathrm{Li}_{2} \mathrm{O}-\mathrm{BaF}_{2}-\mathrm{B}_{2} \mathrm{O}_{3}$ at a molar ratio of $\mathbf{I}: \mathrm{Li}_{2} \mathrm{O}: \mathrm{BaF}_{2}: \mathrm{B}_{2} \mathrm{O}_{3}=1: 4: 1: 3$. A mixture of $\mathbf{I}$ powders, $\mathrm{Li}_{2} \mathrm{CO}_{3}, \mathrm{BaF}_{2}$, and $\mathrm{H}_{3} \mathrm{BO}_{3}$ was placed into a $\Phi$ $45 \times 45 \mathrm{~mm}$ platinum crucible in batches and melted at $1173 \mathrm{~K}$ in a temperature-programmable electric furnace. The melt was held at this temperature for $24 \mathrm{~h}$ to ensure that it was homogenized. A platinum wire serving as a nucleation center was dipped into the melt, which was rapidly cooled to $1073 \mathrm{~K}$ and then allowed to cool at a rate of $2 \mathrm{~K} / \mathrm{h}$ until I crystals crystallized on the platinum wire. The crystals were subsequently drawn out of the melt and used as the seed crystals. In the following run of growth, the crystallized temperature was firstly determined by a tentative seed crystal method. A seed crystal was attached to a platinum rod, and then slowly dipped into the melt at $20 \mathrm{~K}$ above the crystallized temperature. The temperature was held for $60 \mathrm{~min}$ to dissolve the rough surfaces of the seed crystal, and then decreased to the crystallized temperature in 5 min before the melt was allowed to cool at a rate of 0.2-1.0 K per day. When the growth finished, the crystal was drawn out of the melt and cooled down to room temperature at a rate of $20 \mathrm{~K} / \mathrm{h}$.

\section{Single-Crystal Structure Determination}

A colorless I crystal $\left(0.26 \times 0.20 \times 0.13 \mathrm{~mm}^{3}\right)$ was selected using an optical microscope for single-crystal XRD analysis. The diffraction data were collected by using graphite-monochromatized Mo $K \alpha$ radiation $(\lambda=$ $0.71073 \AA$ ) at 298 (2) K on an Agilent SuperNova Dual diffractometer with an Atlas detector. The collection of the intensity data, cell refinement, and data reduction were carried out with the program CrysAlisPro. ${ }^{1}$ The structure was solved by the direct method with program SHELXS and refined with the least-squares program SHELXL. ${ }^{2}$

Final refinements include anisotropic displacement parameters. The structure was verified using the ADDSYM 
algorithm from the program PLATON, ${ }^{3}$ and no higher symmetry was found. Details of crystal parameters, data collection, and structure refinement are summarized in Table S1. The atomic coordinates and equivalent isotropic displacement parameters are listed in Table S2. The anisotropic displacement parameters are listed in Table S3, and the selected bond distances and angles are presented in Table S4.

\section{Elemental Analysis}

The inductively coupled plasma elemental analysis of I was measured using a Varian Vita-Pro CCD simultaneous inductively coupled plasma-optical emission spectrometer. The crystal samples were dissolved in nitric acid at the boiling point for $1 \mathrm{~h}$. The result, $\mathrm{K}: \mathrm{Ba}: \mathrm{Li}: \mathrm{Al}: \mathrm{B}=2.79: 3.10: 1.91: 4.16: 6.28$, is consistent with the compositions determined by single-crystal XRD analysis.

\section{Thermal Stability}

The thermal stability was investigated by the differential scanning calorimetric (DSC) analysis on a NETZSCH DTA404PC thermal analyzer (the DSC was calibrated with $\mathrm{Al}_{2} \mathrm{O}_{3}$ ) in an atmosphere of flowing $\mathrm{N}_{2}$. About $21.2 \mathrm{mg}$ I powders were placed into an $\mathrm{Al}_{2} \mathrm{O}_{3}$ crucible, heated at a rate of $20 \mathrm{~K} \mathrm{~min}^{-1}$ from room temperature to $1373 \mathrm{~K}$, and then cooled to room temperature at the same rate.

\section{Second-Harmonic Generation}

The measurements were performed with a Q-switched Nd:YAG laser at a wavelength of $1064 \mathrm{~nm}$. Polycrystalline I samples were ground and sieved into the following particle size ranges: 0-50 $\mu \mathrm{m}, 50-75 \mu \mathrm{m}$, 75-125 $\mu \mathrm{m}, 125-188 \mu \mathrm{m}, 188-250 \mu \mathrm{m}$, and 250-300 $\mu \mathrm{m}$. Crystalline $\mathrm{KH}_{2} \mathrm{PO}_{4}(\mathrm{KDP})$ samples were also ground and sieved into the same particle size ranges and used as the references for second-harmonic generation (SHG) tests. The samples were pressed between glass slides and secured with tape in 1-mm thick aluminum holders containing an 8-mm diameter hole. They were then placed into a light-tight box and irradiated with the laser of $1064 \mathrm{~nm}$. The intensity of the frequency-doubled output emitted from the samples was collected by a photomultiplier tube.

\section{Computational Methods}

The first-principles calculations were performed by the plane-wave pseudopotential method implemented in the CASTEP package based on the density functional theory. ${ }^{4}$ The ion-electron interactions were modeled by the optimized normal-conserving pseudopotentials for all elements. ${ }^{5}$ The generalized gradient approximation (GGA) with Perdew-Burke-Ernzerhof (PBE) functionals was adopted. ${ }^{6}$ The kinetic energy cutoffs of $1000 \mathrm{eV}$ and Monkhorst-Pack k-point meshes ${ }^{7}$ with the spanning of less than $0.07 / \AA^{3}$ in the Brillouin zone were chosen. Based on the calculated electronic structures, the refractive indices $n$ (and the birefringence $\Delta n$ ) can be obtained. 
Meanwhile, the SHG coefficients $d_{\mathrm{ij}}$ were calculated using an expression developed by lin et al. ${ }^{8}$ In addition, to verify the structural stability, the linear response $\operatorname{method}^{9}$ was employed to obtain the phonon dispersion of $\mathbf{I}$ and

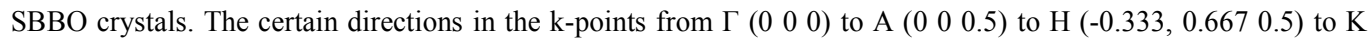
$(-0.333,0.667,0)$ to $\Gamma\left(\begin{array}{lll}0 & 0 & 0\end{array}\right)$ to $\Lambda(0,0.5,0.5)$ to $\mathrm{M}(0,0.5,0)$ to $\mathrm{H}(-0.333,0.667,0.5)$ represent other high symmetry paths in the Brillouin Zone. Our tests reveal that the above computational parameters are sufficiently accurate for present purposes. 


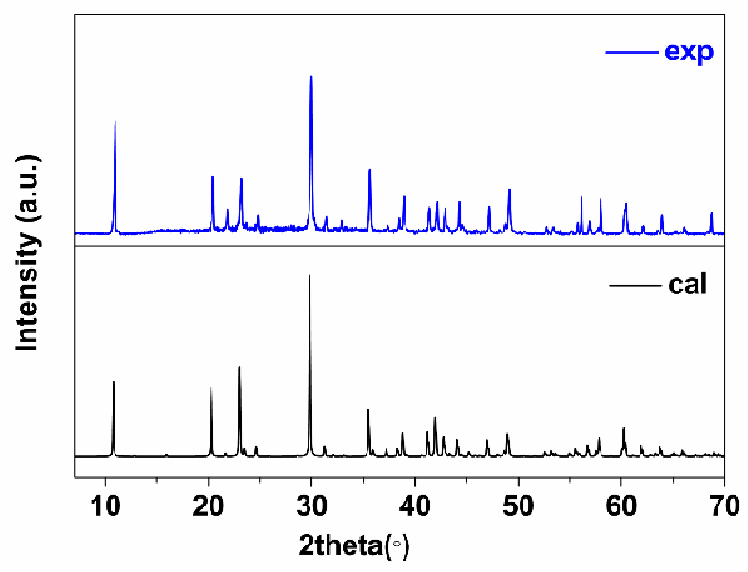

Figure S1. Experimental and calculated XRD patterns of $\mathbf{I}$.

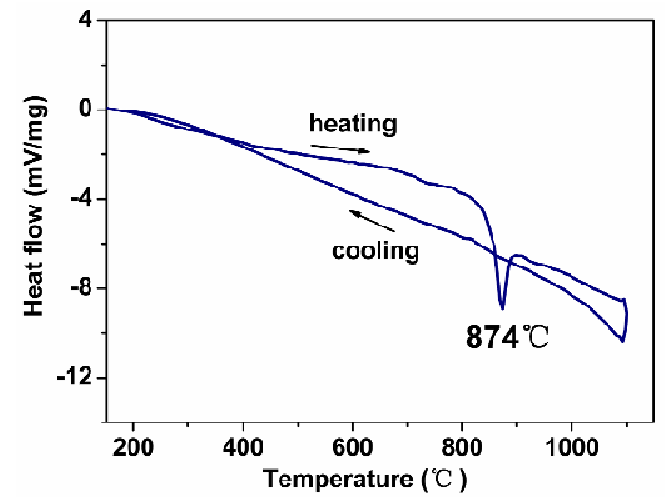

Figure S2. DSC curves of $\mathbf{I}$.

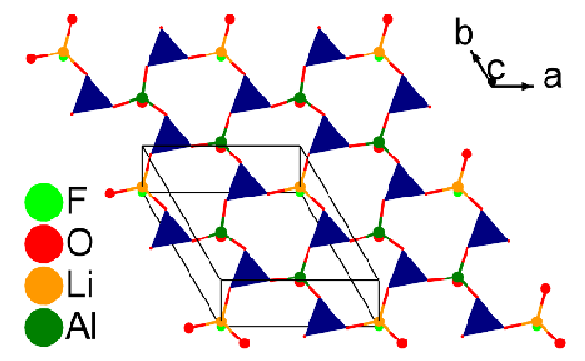

Figure S3. $\left[\mathrm{LiAl}_{2} \mathrm{~B}_{3} \mathrm{O}_{10} \mathrm{~F}\right]_{\infty}$ single-layer. Blue triangles represent $\left[\mathrm{BO}_{3}\right]^{3-}$ groups. 


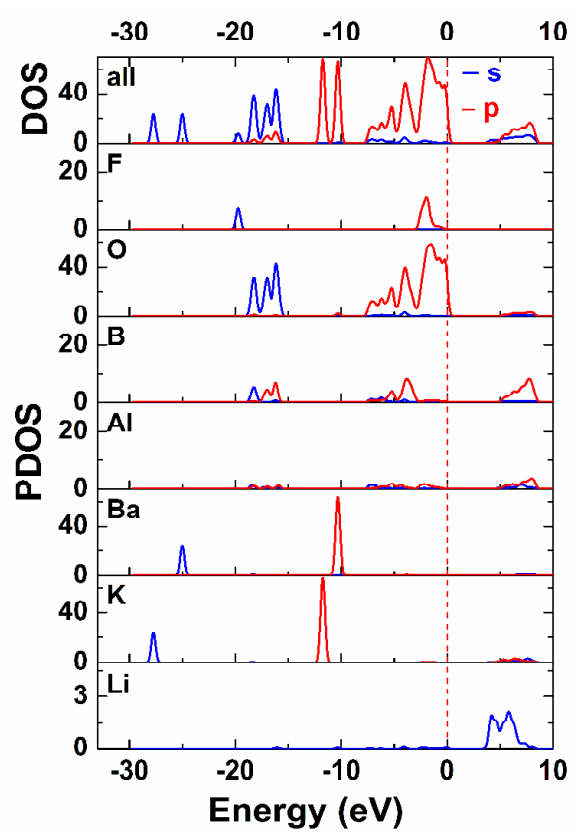

Figure S4. Density of states and partial density of states plots of $\mathbf{I}$.

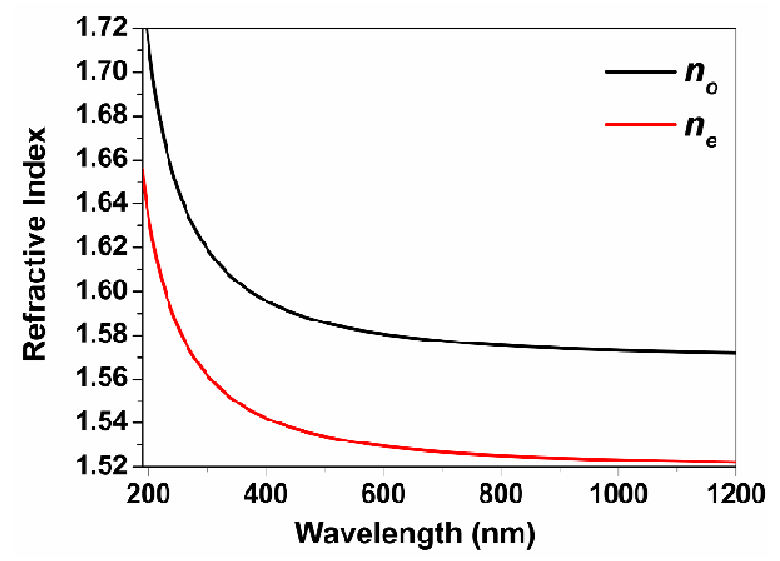

Figure S5. Dispersion curves of refractive index of $\mathbf{I}$. 
Table S1. Crystal data and structure refinement for I

\begin{tabular}{|c|c|}
\hline Formula sum & $\mathrm{K}_{3} \mathrm{Ba}_{3} \mathrm{Li}_{2} \mathrm{Al}_{4} \mathrm{~B}_{6} \mathrm{O}_{20} \mathrm{~F}$ \\
\hline Formula weight (g/mol) & 1054.98 \\
\hline Crystal color & colorless \\
\hline Crystal size $/ \mathrm{mm}$ & $0.26 \times 0.20 \times 0.13$ \\
\hline Crystal system & hexagonal \\
\hline Space group & $P \overline{6} 2 c(190)$ \\
\hline$a / \AA$ & $8.7547(3)$ \\
\hline$c / \AA ̊$ & $16.4346(9)$ \\
\hline$V / \AA^{3}$ & $1090.87(8)$ \\
\hline$Z$ & 2 \\
\hline$\mu / \mathrm{mm}^{-1}$ & 6.190 \\
\hline$F(000)$ & 964 \\
\hline Data/restraints/parameters & $773 / 0 / 63$ \\
\hline$R$ (int) & 0.0220 \\
\hline $\operatorname{GOF}\left(F^{2}\right)$ & 1.089 \\
\hline Flack parameter & $0.03(4)$ \\
\hline Final $R$ indices $\left[F_{\mathrm{o}}^{2}>2 \sigma\left(F_{\mathrm{c}}^{2}\right)\right]^{a}$ & $R_{1}=0.0220, \mathrm{w} R_{2}=0.0524$ \\
\hline Final $R$ indices (all data) ${ }^{a}$ & $R_{1}=0.0232, \mathrm{w} R_{2}=0.0534$ \\
\hline
\end{tabular}


Table S2. Atomic coordinates and equivalent isotropic displacement parameters for I

\begin{tabular}{|c|c|c|c|c|c|c|c|}
\hline Atom & Wyck. & Site & S.O.F. & $x / a$ & $y / b$ & $z / c$ & $U\left[\AA^{2}\right]^{a}$ \\
\hline Ba1 & $6 \mathrm{~h}$ & m.. & & $0.01235(3)$ & $0.31625(4)$ & $3 / 4$ & $0.01337(16)$ \\
\hline K1 & $6 \mathrm{~g}$ & .2 . & & 0 & $0.29556(19)$ & $1 / 2$ & $0.0255(3)$ \\
\hline Li1 & $4 \mathrm{e}$ & 3. & & 0 & 0 & $0.8851(8)$ & $0.006(3)$ \\
\hline Al1 & $4 \mathrm{f}$ & 3.. & & $1 / 3$ & $2 / 3$ & $0.89627(18)$ & $0.0120(5)$ \\
\hline $\mathrm{A} 12$ & $4 \mathrm{f}$ & $3 .$. & & $2 / 3$ & $1 / 3$ & $0.89557(17)$ & $0.0121(5)$ \\
\hline B1 & $12 \mathrm{i}$ & 1 & & $0.3505(8)$ & $0.3455(7)$ & $0.8565(5)$ & $0.0172(15)$ \\
\hline $\mathrm{O} 1$ & $4 \mathrm{f}$ & $3 .$. & & $2 / 3$ & $1 / 3$ & $0.9999(2)$ & $0.042(3)$ \\
\hline $\mathrm{O} 2$ & $12 \mathrm{i}$ & 1 & & $0.5319(4)$ & $0.4141(4)$ & $0.85993(16)$ & $0.0265(8)$ \\
\hline $\mathrm{O} 3$ & $12 \mathrm{i}$ & 1 & & $0.2917(4)$ & $0.4654(5)$ & $0.85685(18)$ & $0.0305(8)$ \\
\hline $\mathrm{O} 4$ & $12 \mathrm{i}$ & 1 & & $0.2334(5)$ & $0.1732(5)$ & $0.85440(18)$ & $0.0275(7)$ \\
\hline F1 & $2 \mathrm{a}$ & 32. & & 0 & 0 & 1.00000 & $0.028(2)$ \\
\hline
\end{tabular}

${ }^{a} U_{\text {eq }}$ is defined as one-third of the trace of the orthogonalized $U_{\mathrm{ij}}$ tensor. 
Table S3. Anisotropic displacement parameters $\left(\AA^{2}\right)$ for I

\begin{tabular}{|c|c|c|c|c|c|c|}
\hline Atom & $U_{11}$ & $U_{22}$ & $U_{33}$ & $U_{12}$ & $U_{13}$ & $U_{23}$ \\
\hline $\mathrm{Ba} 1$ & $0.0096(2)$ & $0.0102(2)$ & $0.0188(2)$ & $0.00384(17)$ & 0.00000 & 0.00000 \\
\hline K1 & $0.0275(9)$ & $0.0236(5)$ & $0.0269(8)$ & $0.0138(5)$ & $0.0055(4)$ & $0.0027(2)$ \\
\hline B1 & $0.022(3)$ & $0.017(3)$ & $0.012(3)$ & $0.009(3)$ & $0.003(2)$ & $0.003(2)$ \\
\hline F1 & $0.038(3)$ & $0.038(3)$ & $0.009(3)$ & $0.0188(16)$ & 0.00000 & 0.00000 \\
\hline Li1 & $0.005(4)$ & $0.005(4)$ & $0.007(6)$ & $0.002(2)$ & 0.00000 & 0.00000 \\
\hline Al1 & $0.0071(7)$ & $0.0071(7)$ & $0.0220(13)$ & $0.0035(4)$ & 0.00000 & 0.00000 \\
\hline $\mathrm{A} 12$ & $0.0093(8)$ & $0.0093(8)$ & $0.0175(13)$ & $0.0047(4)$ & 0.00000 & 0.00000 \\
\hline $\mathrm{O} 1$ & $0.057(4)$ & $0.057(4)$ & $0.014(4)$ & $0.028(2)$ & 0.00000 & 0.00000 \\
\hline $\mathrm{O} 2$ & $0.013(2)$ & $0.0171(16)$ & $0.0510(17)$ & $0.0084(19)$ & $0.0000(14)$ & $0.0111(13)$ \\
\hline $\mathrm{O} 3$ & $0.0226(17)$ & $0.015(2)$ & $0.0573(17)$ & $0.012(2)$ & $-0.0177(14)$ & $-0.0116(18)$ \\
\hline $\mathrm{O} 4$ & $0.016(2)$ & $0.012(2)$ & $0.0506(16)$ & $0.0035(15)$ & $0.0104(16)$ & $-0.0056(16)$ \\
\hline
\end{tabular}


Table S4. Selected bond distances $(\AA)$ and angles (deg.) for I

\begin{tabular}{|c|c|c|c|}
\hline $\mathrm{Ba} 1-\mathrm{O} 4^{\mathrm{i}}$ & $2.639(3)$ & $\mathrm{K} 1-\mathrm{F} 1^{\mathrm{vi}}$ & $2.5876(16)$ \\
\hline $\mathrm{Ba} 1-\mathrm{O} 4^{\mathrm{ii}}$ & $2.639(3)$ & $\mathrm{K} 1-\mathrm{O} 4^{\mathrm{vii}}$ & $3.024(3)$ \\
\hline $\mathrm{Ba} 1-\mathrm{O} 3^{\mathrm{iii}}$ & $2.753(3)$ & $\mathrm{K} 1-\mathrm{O} 4^{\mathrm{i}}$ & $3.024(3)$ \\
\hline $\mathrm{Ba} 1-\mathrm{O} 2^{\mathrm{iv}}$ & $2.801(3)$ & $\mathrm{K} 1-\mathrm{O} 1^{\mathrm{vii}}$ & $3.0968(9)$ \\
\hline $\mathrm{Ba} 1-\mathrm{O} 2^{\mathrm{v}}$ & $2.801(3)$ & $\mathrm{K} 1-\mathrm{O} 1^{\mathrm{v}}$ & $3.0968(9)$ \\
\hline $\mathrm{Ba} 1-\mathrm{O} 4^{\mathrm{iii}}$ & $3.268(3)$ & $\mathrm{K} 1-\mathrm{O} 2^{\mathrm{v}}$ & $3.194(3)$ \\
\hline $\mathrm{Li} 1-\mathrm{F} 1$ & $1.889(13)$ & $\mathrm{K} 1-\mathrm{O} 2^{\mathrm{viii}}$ & $3.194(3)$ \\
\hline $\mathrm{Li} 1-\mathrm{O} 4^{\mathrm{xvi}}$ & $1.905(5)$ & $\mathrm{K} 1-\mathrm{O} 3^{\mathrm{iii}}$ & $3.236(3)$ \\
\hline $\mathrm{Li} 1-\mathrm{O} 4^{\mathrm{ii}}$ & $1.905(5)$ & $\mathrm{K} 1-\mathrm{O} 3^{\mathrm{ix}}$ & $3.236(3)$ \\
\hline Li1-O4 & $1.905(5)$ & $\mathrm{A} 12-\mathrm{O} 2^{\mathrm{xviii}}$ & $1.752(3)$ \\
\hline $\mathrm{B} 1-\mathrm{O} 4$ & $1.335(7)$ & $\mathrm{A} 12-\mathrm{O} 2^{\mathrm{xix}}$ & $1.752(4)$ \\
\hline $\mathrm{B} 1-\mathrm{O} 3$ & $1.381(6)$ & $\mathrm{A} 12-\mathrm{O} 1$ & $1.715(4)$ \\
\hline $\mathrm{B} 1-\mathrm{O} 2$ & $1.390(6)$ & $\mathrm{A} 12-\mathrm{O} 2$ & $1.752(3)$ \\
\hline $\mathrm{O} 4-\mathrm{B} 1-\mathrm{O} 3$ & 119.5(4) & $\mathrm{A} 11-\mathrm{O} 3$ & $1.736(4)$ \\
\hline $\mathrm{O} 4-\mathrm{B} 1-\mathrm{O} 2$ & $123.7(4)$ & $\mathrm{A} 11-\mathrm{O}^{\mathrm{xvii}}$ & $1.706(4)$ \\
\hline \multirow[t]{2}{*}{$\mathrm{O} 3-\mathrm{B} 1-\mathrm{O} 2$} & $116.8(4)$ & $\mathrm{A} 11-\mathrm{O} 3^{\mathrm{iv}}$ & $1.736(4)$ \\
\hline & & $\mathrm{A} 11-\mathrm{O}^{\mathrm{xi}}$ & $1.736(4)$ \\
\hline
\end{tabular}

Symmetry codes: (i) -y, x-y, 1.5-z; (ii) -y, x-y, z; (iii) x, y, 1.5-z; (iv) -x+y, 1-x, z; (v) -x+y, 1-x, 1.5-z; (vi) -x+y, -x, 1.5-z; (vii) y, x, -0.5+z; (viii) x-y, 1-y, -0.5+z; (ix) -x, -x+y, -0.5+z; (x) -1+y, x, -0.5+z; (xi) 1-y, 1+x-y, z; (xii) x-y, -y, 2-z; (xiii) 1-y, 1+x-y, 1.5-z; (xiv) 1+x-y, 1-y, 2-z; (xv) 1+x, y, 1.5-z; (xvi) -x+y, -x, z; (xvii) x-y, 1-y, 2-z; (xviii) 1-y, x-y, z; (xix) 1-x+y, 1-x, z. 


\section{References:}

(1) CrysAlisPro, Version 1.171.36.28; Agilent Technologies: Santa Clara, CA, 2013.

(2) Sheldrick, G. M. Acta Crystallogr. A 2008, 64, 112.

(3) Spek, A. L. J. Appl. Crystallogr. 2003, 36, 7.

(4) (a) Kohn, W.; Sham, L. J. Phys. Rev. 1965, 140, A1133; (b) Payne, M. C.; Teter, M. P.; Allan, D. C.; Arias, T. A.; Joannopoulos, J. D. Rev. Mod. Phys. 1992, 64, 1045; (c) Clark, S. J.; Segall, M. D.; Pickard, C. J.; Hasnip, P. J.; Probert, M. J.; Refson, K.; Payne, M. C. Z. Kristallogr. 2005, 220, 567.

(5) Rappe, A. M.; Rabe, K. M.; Kaxiras, E.; Joannopoulos, J. D. Phys. Rev. B 1990, 41, 1227.

(6) Perdew, J. P.; Zunger, A. Phys. Rev. B 1981, 23, 5048.

(7) Monkhorst, H. J.; Pack, J. D. Phys. Rev. B 1976, 13, 5188.

(8) (a) Lin, J.; Lee, M. H.; Liu, Z. P.; Chen, C. T.; Pickard, C. J. Phys. Rev. B 1999, 60, 13380; (b) Lin, Z. S.; Jiang, X. X.; Kang, L.; Gong, P. F.; Luo, S. Y.; Lee, M. H. J. Phys. D-Appl. Phys. 2014, 47, 253001.

(9) Baroni, S.; de Gironcoli, S.; Dal Corso, A.; Giannozzi, P. Rev. Mod. Phys. 2001, 73, 515. 